\title{
Treatment Outcomes with Biosimilars: Be Aware of the Nocebo Effect
}

\author{
Mourad F. Rezk (D) Burkhard Pieper
}

Received: September 1, 2017 / Published online: October 14, 2017

(c) The Author(s) 2017. This article is an open access publication, corrected publication 2021

\begin{abstract}
Over the years, biologic agents have proven their importance in the management of chronic autoimmune diseases, such as rheumatoid arthritis, psoriasis, and inflammatory bowel disease. Biosimilars, which are biologic medicines, are highly similar to approved biologic medicines, and are comprehensively developed and rigorously tested to ensure efficacy and safety are similar to the reference product. A broader armamentarium of biosimilars is expected to improve patients' access to safe and effective biologic medicines, thus offering benefits to healthcare systems around the globe. Here we consider the factors that may compromise the benefits of biosimilars being realized, including
\end{abstract}

Digital Features This article is published with digital features, including a summary slide and slide deck, to facilitate understanding of the article. To view digital features for this article go to www.medengine.com/ Redeem/D3CCF0605B415A56 or see the article's supplementary information.

Enhanced content To view enhanced content for this article go to www.medengine.com/Redeem/ D3CCF0605B415A56.

Supplementary Information The online version contains supplementary material available at https:// doi.org/10.1007/s40744-017-0085-z.

M. F. Rezk $(\bowtie) \cdot$ B. Pieper

Biogen International GmbH, Zug, Switzerland

e-mail: mouradfarouk.rezk@biogen.com patient and physician perception of biosimilars, and an often overlooked factor, the nocebo effect, which is re-emerging with the widespread adoption of biosimilar medicines. We have also described a variety of strategies and recommendations that could help limit the nocebo effect.

Funding: Biogen.

Keywords: Adherence; Biologic; Biosimilar; Nocebo

\section{INTRODUCTION}

Advanced biologic medicines have been widely used in changing the course of many chronic and life-threatening diseases. The high cost of these biologics is an increasing burden to healthcare systems and limiting their sustainable accessibility to patients. The loss of exclusivity of many biologics and the setting of a clear and robust regulatory approval pathway have paved the way for the introduction of more affordable biosimilars that, once developed, are rigorously evaluated to ensure similar molecular structure, efficacy, and safety to their reference biologics. Since 2007, more than 20 biosimilars have been approved by the European Medical Association (EMA), including the first biosimilar monoclonal antibody (mAb) CT-P13 (infliximab biosimilar), which was followed by SB4 (etanercept biosimilar) and SB2 (infliximab biosimilar) 
for the treatment of autoimmune diseases, such as rheumatoid arthritis, psoriatic arthritis, axial spondyloarthritis, psoriasis, and inflammatory bowel disease $[1,2]$. Further biosimilars that have recently received EMA approval include ABP501 (adalimumab biosimilar), GP2015 (etanercept biosimilar), and GP2013 and CT-P10 (rituximab biosimilars) [3]. Collectively, these biosimilars have helped reduce the overall spend and also increased patient access to effective biologic treatment [4].

Nevertheless, surveys of patients' and clinicians' views clearly demonstrate important gaps in their level of awareness and perception of biosimilars, which occasionally trigger feelings of uncertainty and ungrounded negative attitudes towards prescribing or receiving biosimilars [5-7]. The role of negative perceptions and attitudes were previously described and are known to have the potential to negatively impact adherence and treatment outcomes [8-10]. Different publications have described this as the nocebo effect, which is the negative equivalent to a placebo effect, and have looked into its impact on adherence to medications [11-13]. Special attention has been given to the nocebo effect on the adherence to generics, and different researchers have explored the potential nocebo mechanisms and proposed approaches to minimize it $[9,11]$. In our paper, we will specifically draw additional light on the nocebo effect to help optimize the use of, and adherence to, biosimilars and hence ensure favorable and sustainable clinical outcomes.

This article is based on previously conducted studies, and does not involve any new studies of human or animal subjects performed by any of the authors.

\section{Perception of Biosimilars: Awareness and Communication Gaps}

For reference biologics, the aim of the developmental process is to demonstrate de novo the risk-benefit profile of the candidate product [1]. However, during biosimilar development, the aim is to demonstrate high biosimilarity with the reference biologic in terms of structure, physicochemical attributes, and biologic activity, and to reconfirm the efficacy, safety, and immunogenicity profile as it was previously established by the reference biologic during its development process [1]. The majority of effort in establishing similarity is performed during comprehensive non-clinical comparability exercises, whereupon any potential difference in terms of critical quality attributes between the biosimilar and reference biologic are more likely to be detected (Fig. 1) [14]. Following this, and to achieve regulatory approval, a phase I pharmacokinetic clinical study in humans must be carried out to demonstrate pharmacokinetic equivalence. At least one phase III, randomized clinical trial is then performed in a sensitive patient population representative of those included in an approved indication for the reference biologic, to demonstrate equivalent efficacy and comparable safety and immunogenicity of the biosimilar and its reference biologic. Post-marketing authorization studies, together with real-world data from registries and clinical centers, provide additional confirmation for the long-term effectiveness, safety, and immunogenicity of approved biosimilars [2, 15-21]. All this taken together comprises the totality of evidence for a biosimilar, highlighting the rigorous process in which biosimilars are developed and monitored [2].

However, despite biosimilars having been available since 2007 and, although vast amounts of preclinical, clinical, and real-world evidence confirming similar quality, equivalent efficacy, and comparable safety of the biosimilars to their reference biologic are available, a perception gap (likely due to low awareness of available data and lack of communication of these data) among physicians and patients still exists [5-7]. Although the majority of physicians are aware of biosimilars, knowledge gaps regarding the effectiveness and safety of these molecules can sometimes exist, which may lead to uncertainties around their use in daily clinical practice [5]. Patient knowledge, understanding and perception of biosimilars also play an important role with regard to acceptance and treatment outcomes. Patients who are aware of biosimilars tend to have more positive perceptions regarding biosimilars than patients who 


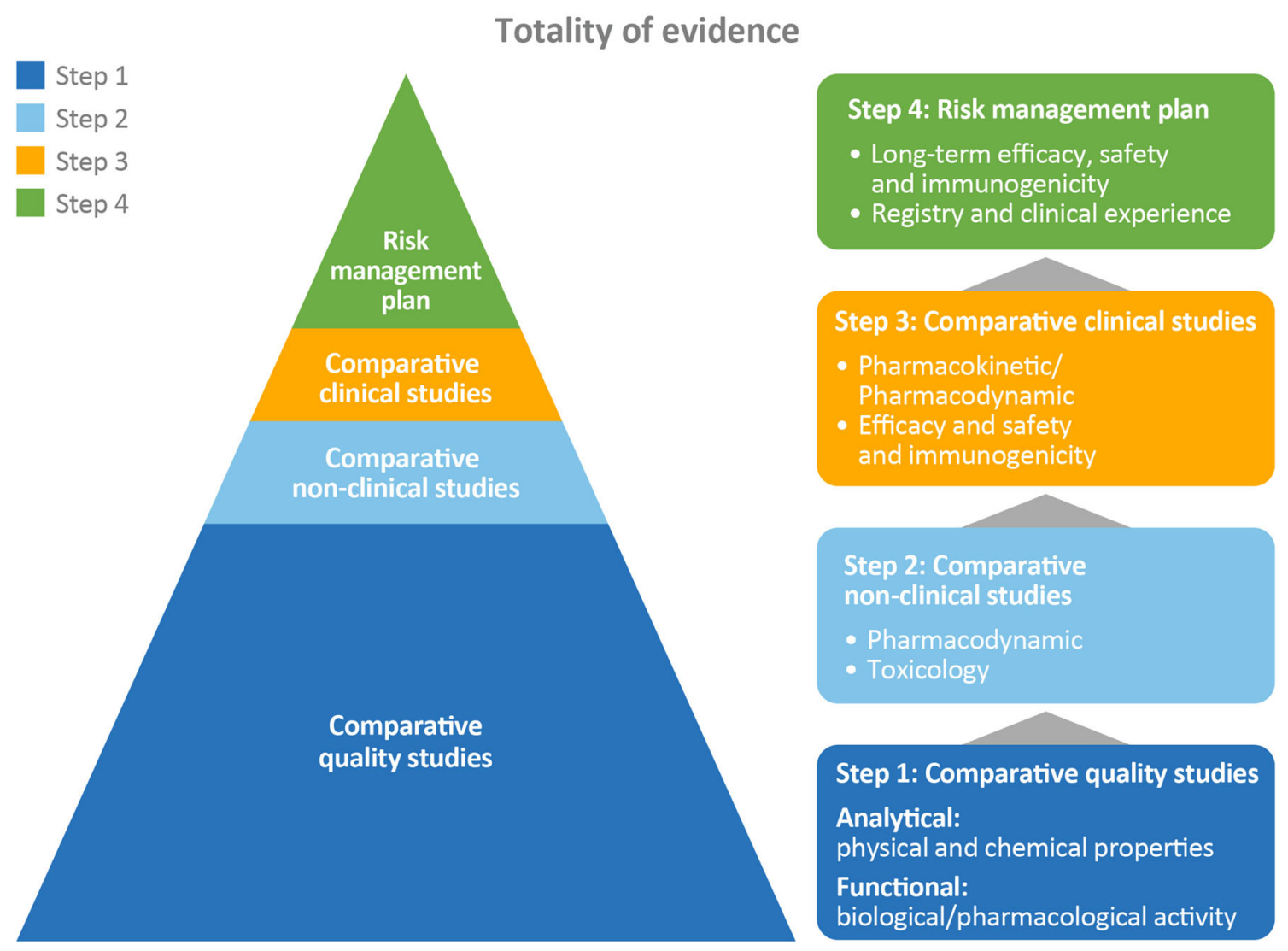

Fig. 1 Data requirements for approval of a biosimilar [14]. Regulatory agencies in the EU and USA have defined a pathway for the development of a biosimilar that is designed to leverage the existing information and clinical experience from the reference product, resulting in reduced clinical trials for the biosimilar candidate and a greater preponderance of analytical characterization as well as non-clinical and clinical pharmacology data. In order for the biosimilar candidate to leverage the clinical history of the reference product, the biosimilar must demonstrate

are unaware; however, perception regarding efficacy and safety of reference biologics is higher than for biosimilars [7]. Therefore, low awareness and misconceptions of biosimilars may create, or widen, gaps in physician and patient perceptions, thereby impacting the use of biosimilars (as patients are less comfortable switching) and their outcomes [7].

In general, patient perception of treatment is also important when considering treatment adherence because a negative perception of treatment efficacy can cause non-adherence, as can lack of knowledge about a disease and its analytically similarity to the reference product. The higher the similarity at the analytical level, the lower the uncertainty will be that the biosimilar will behave differently at the clinical level. This is a stepwise approach to establishing biosimilarity where each step must be satisfied as no steps can refute significant differences in the preceding steps. Adapted from Biosimilars in the EU. Available at: http://www.ema.europa.eu/docs/en_GB/ document_library/Leaflet/2017/05/WC500226648.pdf (Accessed August 2017)

treatment [22]. In addition, drug profiles play an important role, with patients more likely to discontinue treatment due to a poor side-effect profile or lack of efficacy of a medication [23]. For example, in patients with rheumatoid arthritis, discontinuation rates due to inefficacy and adverse events were demonstrated in etanercept (17.5 and $22.4 \%$, respectively), infliximab (44.1 and $36.7 \%$, respectively) and adalimumab (50.4 and $31.2 \%$, respectively) over a period of 12 years. These data highlight the importance efficacy and safety of a medication plays in patient adherence to treatment [23]. 


\section{A Common Phenomenon Known as the Nocebo Effect Can Impact Outcomes}

Perception gaps may be related to a nocebo effect that can lead to the induction or the worsening of symptoms induced by sham or active therapies $[24,25]$. When a nocebo effect is seen with an active therapy, this is a non-specific response in that the symptoms or physiologic changes cannot be explained on the basis of the known pharmacology of the drug and is not dose-dependent [11]. Nocebo symptoms are typically generalized and diffuse, including drowsiness, nausea, fatigue, and insomnia [26].

Patients in general are highly receptive, but women, patients with psychiatric illness, or individuals with certain personality traits (e.g., aggressive or competitive) have been shown to be more susceptible to a nocebo effect [26-28]. Psychologic mechanisms, including classic conditioning (when a neutral, inert or inactive stimulus can elicit a physiologic change if these have previously been repeatedly paired with a provocative stimulus), negative expectations and suggestibility can underlie the nocebo effect $[11,29]$. A perceived increase in dose of medication, suggestions by healthcare professionals (HCPs) that the medication triggers symptoms, observations of other people experiencing symptoms and higher expectations of symptoms are also strong predictors of the nocebo effect [24]. Verbal and non-verbal communications from the HCP that may contain unintentional negative connotations [24], such as "this medication may help" or "let's try this drug", may also trigger a nocebo response in patients [24].

This effect has previously been observed in several therapy areas, including pain, Parkinson's disease, and cardiovascular disease [12, 30-33]. The nocebo effect was very recently demonstrated in patients receiving statins, where an excess rate of muscle-related adverse events were reported only when patients and their doctors were aware that statin therapy was being used, and not when its use was blinded [31]. It is also very well recognized in patients who switch from a reference medicine to chemically identical generics [34, 35].

\section{Nocebo Effect in Patients Prescribed Biosimilar Agents}

Recently, this nocebo effect has also been considered in patients switching from reference biologics to biosimilars $[15,18,36]$. In observational studies, $16-28 \%$ of patients were found to discontinue CT-P13 biosimilar following $\geq 3$ months of treatment $[15,18,36]$. Additionally, it was suggested that these discontinuation rates might have been slightly higher than those historically reported with the reference biologic and that this difference could be partially explained by perceived loss of efficacy and minor adverse events (such as fatigue, malaise, and headache), despite no changes in efficacy, safety, or immunogenicity being observed $[15,18,36]$. The authors concluded a nocebo effect was likely; however, they recommended further investigation to fully understand this phenomenon with regard to biosimilar use. The discontinuation rates stated in these publications are higher than those seen in registries and clinical center studies in patients treated with the etanercept biosimilar, with some reporting $\leq 9 \%$ discontinuation rate following $\geq 5$ months of treatment $[16,17,19-21]$. Interestingly, these are far lower than those seen in Turkey, where medical billing records from patients with rheumatoid arthritis were analyzed, and 63 and $82 \%$ of biologic-naïve and switch patients (from INF to CT-P13), respectively, discontinued biosimilar treatment $[37,38]$. However, the authors of these studies concluded further analysis was required to understand the reasons for these observations.

\section{Overall Consequences of the Nocebo Effect}

Considering that the nocebo effect has been shown to impact the number of adverse events experienced by a patient, result in perceived loss of efficacy, and lead to non-adherence to a medicine, the consequences to the healthcare system are far-reaching. Not only does this affect patients' quality of life, but it can also affect how HCPs resolve these additional adverse events, which can lead to more 
complicated treatment regimens, or needless switching of the patient to previous treatments and possibly reducing their future treatment options. Collectively, dealing with nocebo effects results in additional patient clinic visits, which places more pressure on a healthcare system and can lead to the cost savings of biosimilars not being realized [11, 39].

\section{Strategies to Minimize the Possibility of a Nocebo Effect with Biosimilar Agents}

Given that the nocebo effect can prompt non-adherence, which can have far-reaching consequences for a patient and healthcare systems [11], it is recommended that HCPs employ interventions to help minimize these effects from occurring. Invariably, owing to time restrictions in a busy clinic, it can be challenging to perform a thorough patient-physician discussion to ensure informed shared decision-making and reduce the likelihood of a nocebo effect from occurring. However, various strategies can be implemented in the clinic to help informed decision-making and negate the nocebo effect, including identifying patients at high risk, determining patient expectations of adverse events and providing reassurance if these are excessive, tailoring information to only provide pertinent details to the patient (Fig. 2) [7], reducing exposure of the patient to others experiencing side effects, and educating the patient on nocebo effects using case studies [25, 39]. Physicians should consider implementing motivational interviewing techniques into the clinic by subtly guiding the patient to think about and verbally express their reasons for and against change, so that the patient is making an informed and considered choice, which is likely to help reduce the nocebo effect [40]. In addition, any HCP who talks to patients about the potential use of a biosimilar must themselves feel fully confident and capable of transferring this confidence, and help a patient make an informed shared decision, without unintended negative suggestions, which may trigger an inappropriate negative bias and a nocebo response.

Information on biosimilars is now available from several distinct sources that help to inform and build HCP confidence when making informed shared treatment decisions with their patients. This includes data from clinical trials, data from large observational registries, data from individual case studies, institutional experiences, and information guides released by regulatory bodies [14]. Well-informed HCPs who are aware of these data are more likely to become confident and then be able to transfer this confidence in biosimilar medication to their patients, resulting in patient confidence regarding their choice, whether they eventually choose to switch or not, which should alleviate the

\section{Checklist for HCPs of the information needed for patients to make informed decisions about biosimilar use}

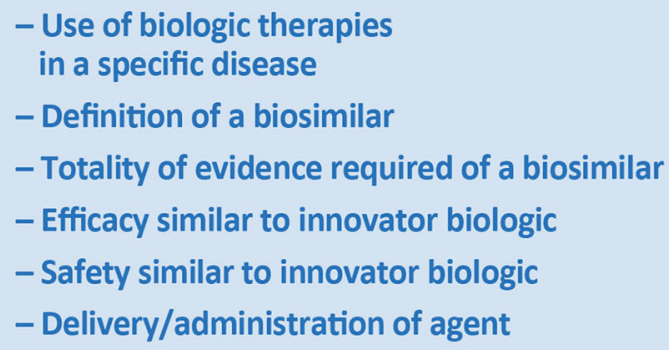

Fig. 2 A checklist for HCPs with the information needed for patients to make informed decisions about biosimilar use. Patient Preference and Adherence by Dove Press
- Devices use (if applicable)

- Access to treatment

- Insurance coverage/out-of-pocket cost

- Services available to support the patient

- Clinical trials including standard biosimilar trial design (active innovator comparator; no placebo arm)

- Manufacturer identity 

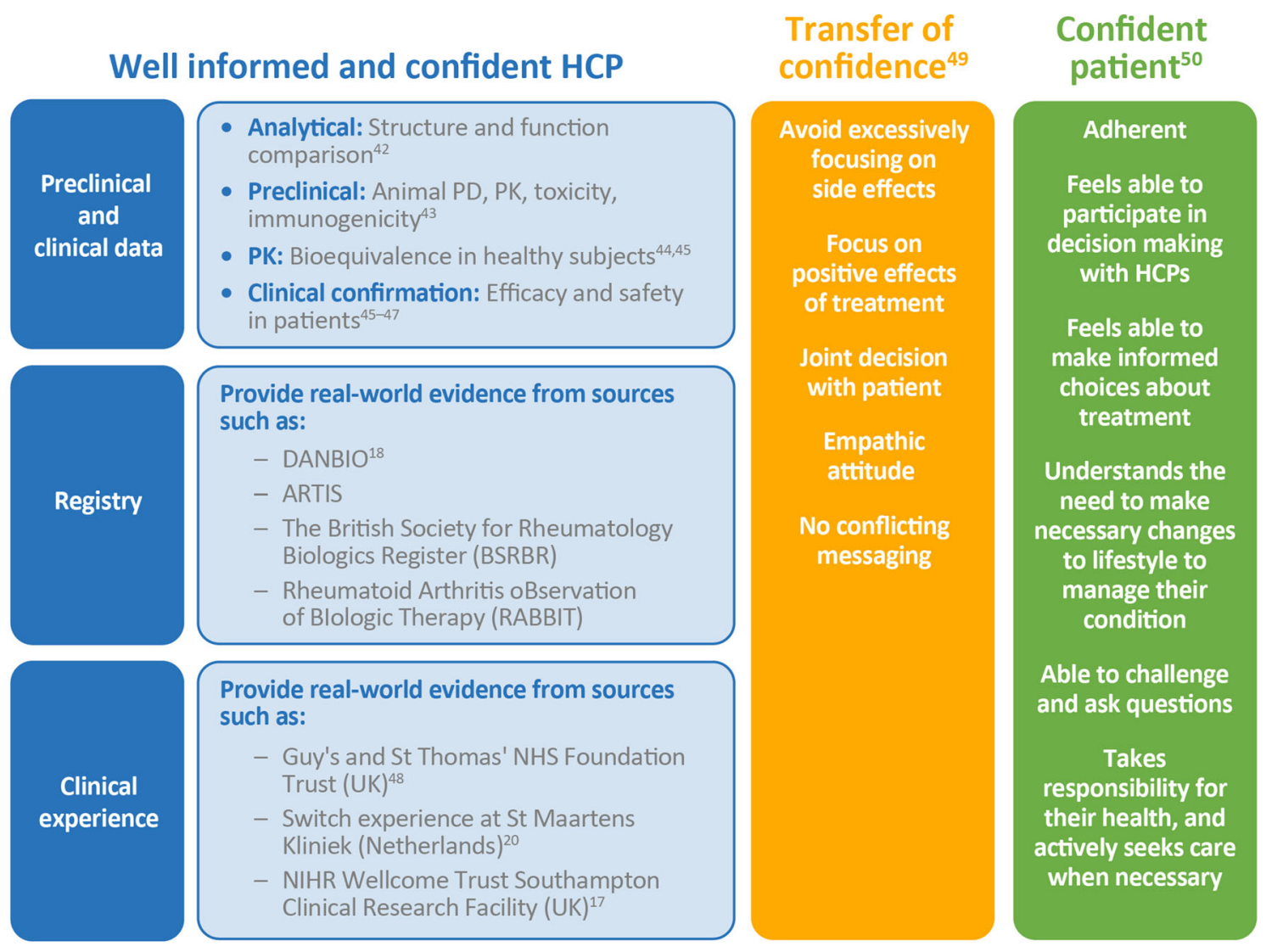

Fig. 3 Confidence of HCPs regarding biosimilar agents results in empowered patient treatment decisions in rheumatoid arthritis. HCPs' awareness of the depth and breadth of biosimilar data and their ability to explain this information effectively to a patient will result in patient confidence in their treatment choice, ultimately leading to an increase in medication adherence and a reduction in the probability of a nocebo effect. The different sources of information available to HCPs to help them gain confidence include RCTs (which demonstrate comparable

nocebo effect (Fig. 3). Emerging research has shown how influential patient-physician interaction is on the perception of efficacy and safety of biosimilars, as it is with other therapies. For example, researchers at the Parker Institute, Denmark, have identified strong barriers and facilitators to the patient experience and highlighted patient-physician interaction as critical to ensure perceived treatment value for the patient. They highlighted that when treatment discussions with patients occur, it is important to appreciate that single biased words and gestures can have a significant impact and should be efficacy and safety between biosimilars and their reference biologics) and an increasing collection of RWE from registries and individual clinical centers that provide further information on use of biosimilars and long-term safety and effectiveness. Furthermore, to assure patient safety, approved biosimilars are under strict pharmacovigilance (the monitoring and tracking of drug safety over time). $H C P$ healthcare professional, $P D$ pharmacodynamics, $P K$ pharmacokinetics, $R C T$ randomized clinical trials, $R W E$ real-world evidence

avoided to ensure minimal negative instructions and negative therapeutic context [39].

Similarly, a recent open-label study compared the effects of switching patients with a rheumatic disease from a reference product to a biosimilar agent (infliximab to CT-P13 in 2016 and etanercept to SB4 in 2017) using different communication strategies, including: notifying all patients at the same time; clearly informing patients about the reasons for the switch; providing 'soft skills' training for rheumatology and pharmacy staff to help them moderate patient concerns; and openly discussing 
possible nocebo effects [20]. They found that this led to higher patient acceptance and persistence rates compared with patients who did not receive this enhanced communication strategy [20]. Further real-world data also show that comprehensive patient education and support (including face-to-face discussions; provision of patient information sheets on drug switch and biosimilars; access to a helpline number and regular clinical reviews) during the switch to a biosimilar product resulted in higher acceptance of these agents by patients, which may also help reduce the nocebo effect $[30,41]$.

\section{CONCLUSIONS}

Although comprehensive comparability studies are used to ensure that biosimilars are approved according to the same quality, safety, and efficacy standards that apply to all biologic medicines [14], information gaps exist that can cause uncertainties amongst physicians and patients, and are heightened by the nocebo effect, which ultimately prevent the full benefits of biosimilars being realized. Given the important role biosimilars play in increasing physician treatment options and patient access to biologic medicine, it is important that HCPs are aware of this nocebo phenomenon and aim to reduce this effect when possible. As this effect could also occur when patients are switched from a reference biologic agent to biosimilar agents, HCPs should ensure they are fully familiar with the available data on biosimilar treatment from trials, registries, and case studies, and also be mindful of their potential to create bias in the mind of the patient through their choice of words and any perceived lack of confidence. Additionally, a thoughtful evaluation of patients' worries and perspectives and addressing them in a constructive and objective manner may further optimize patients' adherence to biosimilars and limit unwanted nocebo effects.

\section{ACKNOWLEDGEMENTS}

This article was funded by Biogen. Article processing charges were funded by Biogen. All named authors meet the International Committee of Medical Journal Editors (ICMJE) criteria for authorship for this manuscript, take responsibility for the integrity of the work as a whole, and have given final approval to the version to be published. Biogen provided funding for medical writing support in the development of this paper; Rugina Ali and Philip Ford, from INC Research/inVentiv Health, wrote the first draft of the manuscript based on input from authors, and Elisabeth Beatty from INC Research/inVentiv Health copyedited and styled the manuscript per journal requirements. The authors had full editorial control of the paper, and provided their final approval of all content.

Disclosures. Mourad Farouk Rezk is an employee of Biogen International $\mathrm{Gmbh}$ and therefore receives a salary and may own Biogen stock. Burkhard Pieper is an employee of Biogen International Gmbh and therefore receives a salary and may own Biogen stock.

Compliance with Ethics Guidelines. This article is based on previously conducted studies, and does not involve any new studies of human or animal subjects performed by any of the authors.

Open Access. This article is distributed under the terms of the Creative Commons Attribution-NonCommercial 4.0 International License (http://creativecommons.org/licenses/ by-nc/4.0/), which permits any noncommercial use, distribution, and reproduction in any medium, provided you give appropriate credit to the original author(s) and the source, provide a link to the Creative Commons license, and indicate if changes were made.

\section{REFERENCES}

1. Rischin A, Östör AJ. Update on biosimilars in rheumatology. Inflammopharmacology. 2017;25: 177-84.

2. Dorner T, Strand V, Cornes P, et al. The changing landscape of biosimilars in rheumatology. Ann Rheum Dis. 2016;75:974-82. 
3. European Public Assessment Reports. http://www. ema.europa.eu/ema/index.jsp?curl=pages/medicines/ landing/epar_search.jsp\&mid=WC0b01ac058001d12 $4 \&$ searchTab=searchByAuthType\&keyword=Enter\% 20keywords\&searchType $=$ name\&alreadyLoaded $=$ true\&status=Authorised\&jsenabled=false\&search GenericType=biosimilars\&orderBy=authDate\&page No=1. Accessed Aug 2017.

4. IMS report. 2016. http://www.medicinesforeurope. com/wp-content/uploads/2016/08/IMS-Impact-ofBiosimilar-Competition-2016.pdf. Accessed Aug 2017.

5. Cohen H, Beydoun D, Chien D, et al. Awareness, knowledge, and perceptions of biosimilars among specialty physicians. Adv Ther. 2017;33:2160-72.

6. Peyrin-Biroulet L, Lönnfors S, Roblin X, Danese S, Avedano L. Patient perspectives on biosimilars: a survey by the European Federation of Crohn's and Ulcerative Colitis Associations. J Crohns Colitis. 2017;11:128-33.

7. Jacobs I, Singh E, Sewell KL, Al-Sabbagh A, Shane LG. Patient attitudes and understanding about biosimilars: an international cross-sectional survey. Patient Prefer Adherence. 2016;10:937-48.

8. Bingel U, Wanigasekera $\mathrm{V}$, Wiech $\mathrm{K}$, et al. The effect of treatment expectation on drug efficacy: imaging the analgesic benefit of the opioid remifentanil. Sci Transl Med. 2011;3:70ra14.

9. Faasse K, Petrie KJ. The nocebo effect: patient expectations and medication side effects. Postgrad Med J. 2013;89:540-6.

10. Rodriguez-Raecke RJ, Doganci B, et al. Insular cortex activity is associated with effects of negative expectation on nociceptive long-term habituation. Neurosci. 2010;30:11363-8.

11. Barsky AJ, Saintfort R, Rogers MP, Borus JF. Nonspecific medication side effects and the nocebo phenomenon. JAMA. 2002;287:622-7.

12. Mitsikostas DD, Mantonakis LI, Chalarakis NG. Nocebo is the enemy, not placebo. A meta-analysis of reported side effects after placebo treatment in headaches. Cephalalgia. 2011;31:550-61.

13. Drici MD, Raybaud F, De Lunardo C, Iacono P, Gustovic P. Influence of the behaviour pattern on the nocebo response of healthy volunteers. Br J Clin Pharmacol. 1995;39:204-6.

14. European Medicines Agency. Biosimilars in the EU. http://www.ema.europa.eu/docs/en_GB/document_ library/Leaflet/2017/05/WC500226648.pdf. Accessed Aug 2017.
15. Nikiphorou E, Kautiainen $\mathrm{H}$, Hannonen $\mathrm{P}$, et al. Clinical effectiveness of CT-P13 (Infliximab biosimilar) used as a switch from Remicade (infliximab) in patients with established rheumatic disease. Report of clinical experience based on prospective observational data. Expert Opin Biol Ther. 2015;15:1677-83.

16. Glintborg B, et al. Clinical outcomes from a nationwide non-medical switch from originator to biosimilar etanercept in patients with inflammatory arthritis after 5 months follow-up. EULAR 2017; Abstract FRI0190. http://scientific.sparx-ip.net/ archiveeular $/ \mathrm{c}=\mathrm{a} \& \mathrm{view}=2 \&$ searchfor $=$ Clinical $\% 20$ outcomes\%20from $\% 20$ a $\% 20$ nationwide $\% 20$ nonmedical\%20switch\%20from $\% 20$ originator\%20to\% 20biosimilar\%20etanercept\%20in\%20patients\%20 with\%20inflammatory\%20arthritis\%20after\%205\% 20months\%20follow-up\&item=2017FRI0190. Accessed Aug 2017.

17. Holroyd C, Wallis D, Bennett S, Clayton P, Edwards CJ. Switching from bio-original etanercept to biosimilar etanercept SB4: Patient acceptability and outcomes in the real world. EULAR 2017; Abstract AB0377. http://scientific.sparx-ip.net/archiveeular/ ?view=2\&searchfor=Switching\%20from\%20bio-original\%20etanercept $\% 20$ to\%20biosimilar\%20etanercept $\% 20$ SB $4: \% 20$ Patient $\% 20$ acceptability $\% 20$ and $\%$ 20outcomes\%20in\%20the\%20real\%20world\&c=a \&item=2017AB0377. Accessed Aug 2017.

18. Glintborg B, Sørensen IJ, Loft AG, et al. A nationwide non-medical switch from originator infliximab to biosimilar CT-P13 in 802 patients with inflammatory arthritis: 1-year clinical outcomes from the DANBIO registry. Ann Rheum Dis. 2017;76:1426-31.

19. Sigurdartorri V, Husmark T, Svärd A. Switching from reference product etanercept to the biosimilar SB4 in a real-life setting: follow-up of 147 patients. Ann Rheum Dis. 2017;76:835.

20. Tweehuysen L, Huiskes VJB, van den Bemt BJF, van den Hoogen FHJ, den Broeder AA. Higher acceptance and persistence rates after biosimilar transitioning in patients with a rheumatic disease after employing an enhanced communication strategy. EULAR 2017; Abstract FRI0200. http://scientific.sparx-ip.net/ archiveeular/?searchfor=Higher\%20acceptance $\% 20$ and $\% 20$ persistence $\% 20$ rates\%20after\%20biosimilar \%20transitioning\%20in\%20patients\%20with\%20a $\% 20$ rheumatic\%20disease\%20after\%20employing\% 20an\%20enhanced\%20communication\%20strategy $\& \mathrm{c}=\mathrm{a} \&$ view=2\&item=2017FRI0200. Accessed Aug 2017.

21. Rabbits R, Jewell T, Marrow KL, et al. Switching to biosimilars: An early clinical review. British Society for Rheumatology National Meeting 2017. UK. 
http://www.abstractsonline.com/pp8/\#!/4205/

presentation/5105. Accessed Aug 2017.

22. Neame R, Hammond A. Beliefs about medications: a questionnaire survey of people with rheumatoid arthritis. Rheumatology. 2005;44:762-7.

23. Favalli EG, Pregnolato F, Biggioggero $\mathrm{M}$, et al. Twelve-year retention rate of first-line tumor necrosis factor inhibitors in rheumatoid arthritis: real-life data from a local registry. Arthritis Care Res (Hoboken). 2016;68:432-9.

24. Häuser W, Hansen E, Enck P. Nocebo phenomena in medicine: their relevance in everyday clinical practice. DtschArzteblInt. 2012;109:459-65.

25. Planès S, Villier $C$, Mallaret $M$. The nocebo effect of drugs. Pharmacol Res Perspect. 2016;4:e00208.

26. Wells RE, Kaptchuk TJ. To tell the truth, the whole truth, may do patients harm: the problem of the nocebo effect for informed consent. Am J Bioeth. 2012;12:22-9.

27. Klosterhalfen S, Kellermann S, Braun S, et al. Gender and the nocebo response following conditioning and expectancy. J Psychosom Res. 2009;66:323-8.

28. Data-Franco J, Berk M. The nocebo effect: a clinicians guide. Aust N Z J Psychiatry. 2013;47:617-23.

29. Atlas LY, Wager TD. How expectations shape pain. Neurosci Lett. 2012;520:140-8.

30. Häuser W, Sarzi-Puttini P, Tölle TR, Wolfe F. Placebo and nocebo responses in randomised controlled trials of drugs applying for approval for fibromyalgia syndrome treatment: systematic review and meta-analysis. Clin Exp Rheumatol. 2012;30(Suppl. 74):78-87.

31. Gupta A, Thompson D, Whitehouse A, et al. Adverse events associated with unblinded, but not with blinded, statin therapy in the Anglo-Scandinavian Cardiac Outcomes Trial-Lipid-Lowering Arm (ASCOT-LLA): a randomised double-blind placebo-controlled trial and its non-randomised non-blind extension phase. Lancet. 2017;389:2473-81.

32. Papadopoulos D, Mitsikostas DD. A meta-analytic approach to estimating nocebo effects in neuropathic pain trials. J Neurol. 2012;259:436-47.

33. Voelker R. Nocebos contribute to host of ills. JAMA. 1996;275:345-7.

34. Weissenfeld J, Stock S, Lüngen M, Gerber A. The nocebo effect: a reason for patients' non-adherence to generic substitution? Pharmazie. 2010;65:451-6.
35. Fasse K, Petrie KJ. The nocebo effect: patient expectations and medication side effects. Postgrad Med. 2013;89:540-6.

36. Tweehuysen L, Huiskes VJB, van den Bemt BJF, van den Hoogen FHJ, den Broeder AA. Clinical and immunogenicity outcomes after switching treatment from innovator infliximab to biosimilar infliximab in rheumatic diseases in daily clinical practice. Arthritis Rheumatol. 2016;68(suppl 10). http://acrabstracts. org/abstract/clinical-and-immunogenicity-outcomesafter-switching-treatment-from-innovator-infliximabto-biosimilar-infliximab-in-rheumatic-diseases-indaily-clinical-practice/. Accessed Aug 2017.

37. Yazici Y, Xie L, Ogbomo A, et al. A descriptive analysis of real-world treatment patterns of innovator infliximab (Remicade) and biosimilar infliximab in a treatment-naïve Turkish rheumatologic disease population. Arthritis Rheumatol. 2016; 68(Suppl. 10). http://acrabstracts.org/abstract/adescriptive-analysis-of-real-world-treatment-patternsof-innovator-infliximab-remicade-and-biosimilarinfliximab-in-a-treatment-naive-turkish-rheumatologic-disease-population/. Accessed Aug 2017.

38. Yazici Y, Xie L, Ogbomo A, et al. A descriptive analysis of real-world treatment patterns in a Turkish rheumatology population that continued innovator infliximab (Remicade) therapy or switched to biosimilar infliximab. Arthritis Rheumatol. 2016; 68(Suppl. 10). http://acrabstracts.org/abstr act/a-descriptive-analysis-of-real-world-treatmentpatterns-in-a-turkish-rheumatology-population-th at-continued-innovator-infliximab-remicade-thera py-or-switched-to-biosimilar-infliximab/. Accessed Aug 2017.

39. Colloca L, Finniss D. Nocebo effects, patient-clinician communication, and therapeutic outcomes. JAMA. 2012;307:567-8.

40. Resnicow K, McMaster F. Motivational Interviewing: moving from why to how with autonomy support. Int J Behav Nutr Phys Act. 2012;9:19.

41. Edwards C, Hetland ML, Kristensen LE, Cuadrado M. Switching patients from originator to biosimilar medications in rheumatoid arthritis: limiting the 'nocebo' effect. EMJ Rheumatol. 2017;4:42-8.

42. Cho IH, Lee N, Song D, et al. Evaluation of the structural, physicochemical, and biological characteristics of SB4, a biosimilar of etanercept. MAbs. 2016;8:1136-55.

43. Marshall L, Hickling T, Bill D, Mahgoub E. Comparing the immunogenicity of the etanercept biosimilar SB4 with the innovator etanercept: another consideration. Ann Rheum Dis. 2016;75:e37. 
44. Lee YJ, Shin D, Kim Y, Kang J, Gauliard A, Fuhr R. A randomized phase 1 pharmacokinetic study comparing SB4 and etanercept reference product (Enbrel $^{\circledR}$ ) in healthy subjects. Br J Clin Pharmacol. 2016;82:64-73.

45. Emery P, Vencovsky J, Sylwestrzak A. Long-term safety and efficacy of sb4 (etanercept biosimilar) in patients with rheumatoid arthritis: comparison between continuing sb4 and switching from etanercept reference product to SB4. Ann Rheum Dis. 2016;75(Suppl. 2):236.

46. Emery P, Vencovský J, Sylwestrzak A, et al. A phase III randomised, double-blind, parallel-group study comparing SB4 with etanercept reference product in patients with active rheumatoid arthritis despite methotrexate therapy. Ann Rheum Dis. 2017;76:51-7.

47. Ben-Horin S, Yavzori $\mathrm{M}$, et al. Cross-immunogenicity: antibodies to infliximab in
Remicade-treated patients with IBD similarly recognise the biosimilar Remsima. Gut. 2016;65:1132-8.

48. Szlumper C, Topping K, Blackler L, et al. Switching to biosimilar etanercept in clinical practice. Rheumatology 2017; Abstract 225. http://www. abstractsonline.com/pp8/\#!/4205/presentation/5120. Accessed Aug 2017.

49. Chavarria V, Vian J, Pereira C, et al. The placebo and nocebo phenomena: their clinical management and impact on treatment outcomes. Clin Ther. 2017;3:477-86.

50. Voshaar MJH, Nota I, van der Laar MAFJ, van den Bemt BJF. Patient-centred care in established rheumatoid arthritis. Best Pract Res Clin Rheumatol. $2015 ; 29: 643-63$. 